\title{
RESUMO
}

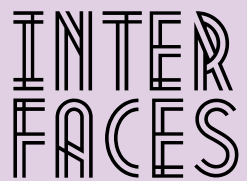

CIENTÍFICAS

\section{DISSIDÊNCIAS SEXUAIS E DE GÊNERO NO HUMOR: ESTIGMA E RESISTÊNCIA ENTRE A TV E A INTERNET}

SEXUAL AND GENDER DISSENTS IN HUMOR: STIGMA AND RESISTANCE BETWEEN TV AND INTERNET

DISIDENCIAS SEXUALES Y DE GÉNERO EN EL HUMOR: ESTIGMA Y RESISTENCIA ENTRE TV Y INTERNET

Rafael Silva de Carvalho ${ }^{1}$

DOSSIE:

"CORPO, GÊNEROE SEXUALIDADE NA CIBERCULTURA: MODOS DE CONHECER, PRÁTICAS DE SOCIABILIDADE E REDES EDUCATIVAS"

0 artigo se trata de uma pesquisa de campo virtual que busca analisar os enunciados, as relações de poder e as produções de subjetividades a partir de dois vídeos humorísticos em torno das dissidências sexuais e de gênero. Os vídeos são esquetes de humor de personagens que marcaram época na televisão brasileira em diferentes décadas (1980 e 1990). 0 método utilizado é a análise do discurso em Michel Foucault, valendo-se dos conceitos de enunciado, verdade, saber, poder e sujeito. Os elementos discursivos foram apreendidos das falas, imagens e comentários dos vídeos selecionados. Adiante, problematizo os resultados da pesquisa no tensionamento entre a produção de estigma e possibilidades de resistência por meio do humor na Televisão e ternet.

\section{PALAVRAS-CHAVE}

Dissidências Sexuais e de Gênero. Humor. Análise do Discurso. Televisão. Internet. 


\section{ABSTRACT}

The article is a virtual field research that seeks to analyze the statements, the power relations and the productions of subjectivities from two humorous videos around sexual and gender dissents. The videos are humor skits of epoch-making characters on Brazilian television in different decades (80 and 90). The method used is the discourse analysis in Michel Foucault, using the concepts of utterance, truth, knowledge, power and subject. The discursive elements were seized from the speeches, images and comments of the selected videos. Ahead, I problematize the results of the research on the tension between stigma production and possibilities of resistance through humor on television and the Internet.

\section{KEYWORDS}

Sexual and gender dissents. Humor. Discourse analysis. Television. Internet.

\section{RESUMEN}

El artículo es una investigación de campo virtual que busca analizar los enunciados, las relaciones de poder y la producción de subjetividades de dos videos humorísticos sobre disidencias sexuales y de género. Los videos son escenas de humor de personajes que marcaron una época en la televisión brasileña en diferentes décadas (80 y 90). El método utilizado es el análisis del discurso en Michel Foucault, utilizando los conceptos de enunciado, verdad, saber, poder y sujeto. Los elementos discursivos fueron tomados de los discursos, imágenes y comentarios de los videos seleccionados. Más adelante, problematizo los resultados de la investigación sobre la tensión entre la producción de estigmas y las posibilidades de resistencia a través del humor en la televisión e Internet.

\section{PALABRAS CLAVE}

disidencias sexuales y de género. Humor. Análisis del discurso. Televisión. Internet. 


\section{ESTUDO TEÓRICO}

Relato a seguir, buscando produções recentes que me ajudassem a compreender melhor a situação do atravessamento do humor virtual na vida das pessoas dissidentes sexuais e de gênero, o resultado comentado da pesquisa bibliográfica realizada. A pesquisa foi feita apenas para trabalhos em português e do Brasil devido a temática tratar da realidade brasileira.

Na página da Scielo (Biblioteca Eletrônica Científica On-line) utilizei como palavras-chave de pesquisa: "humor" + "sexual" e "humor" + "lgbt" nos últimos dez anos, obtendo um total de 15 textos (14 artigos e um artigo de revisão). Desse total, apenas 1 texto se aproxima da temática deste trabalho.

O trabalho de Oliva (2018) defende que as pessoas LGBT podem resistir aos ataques virtuais a partir do humor com o uso de memes ${ }^{2}$.

Na página da Biblioteca Digital Brasileira de Teses e Dissertações (BDTD) utilizei como palavras-chave de pesquisas: "humor", "diversidade" e "sexual" nos últimos dez anos, obtendo um total de 21 trabalhos (14 dissertações e 7 teses). Desse total, obtive 3 trabalhos (2 dissertações e 1 tese) cuja temática auxilia nas conversações deste artigo.

A dissertação de Gonzatti (2017) traz como contribuição um olhar queer ao jornalismo virtual dedicado à cobertura da cultura pop. Dentre as consequências de um jornalismo queer, o autor lembra das possibilidades de desestabilização e enfrentamento (inclusive pelas vias do humor) às normas de sexualidade e gênero que ainda imperam no jornalismo tradicional.

O texto (dissertação) de Mazoti (2018) coloca o canal de YouTube Põe na roda muito mais afinado com o mercado do que com alguma espécie de militância virtual ou resistência.

A tese de Alonso (2010) explica que as gírias das pessoas dissidentes das normas sexuais e de gênero, geram efeitos de humor e riso. Essas gírias podem ser operadas como forma de resistência aos ataques preconceituosos, debochando do agressor que não partilha do mesmo nível de entendimento léxico. Ainda que esse trabalho não se debruce sobre o mundo virtual, optei por citá-lo devido à força que as gírias dissidentes têm na rede, sobretudo no uso de memes e comentários virtuais.

Assim, as pesquisas indicam que se pela via do humor se sofre processos de subalternização, também pela via do humor se criam resistências e ressignificações discursivas. Há ainda uma atenção para as capturas mercadológicas dessas possíveis resistências, ou seja, um cuidado para que uma luta política não se reduza a nicho de mercado.

O que fica em aberto é a tênue fronteira entre alianças políticas e oportunismos midiáticos e de mercado. Ficam ainda mais algumas dúvidas. Qual a melhor forma de disputar visualizações e visibilidades na rede que combatam os estereótipos? Seriam por meio das grandes figuras de repercussão na rede como potenciais aliados ou pelo anonimato viral a exemplo dos memes?

2 Memes podem ser definidos como produções culturais que se difundem voluntariamente via e-mail, mensagens instantâneas, blogs ou redes sociais e ativam "piadas internas" por meio da recriação de outras produções já existentes por intermédio da imitação cômica, satírica ou irônica de seus elementos (BAUCKHAGE, 2011 apud CARNIEL et al., 2018). 


\section{INTRODUÇ̄̃O}

Por muito tempo a televisão produziu (e ainda produz) um certo tipo de humor que engendra subjetividades risíveis das pessoas que desviam das normas sexuais e de gênero. Pretendo trabalhar esse grupo de pessoas não a partir do enfoque identitário, mas apoiado na noção das dissidências sexuais e de gênero, ancorado na leitura de Rubin (2017). Para entender quem são os dissidentes sexuais e de gênero, é preciso remontar ao esquema da pirâmide da hierarquia erótica de que Rubin (2017) se vale para explicar a relação entre práticas sexuais e de gênero com os privilégios sociais de cidadania.

Esses tipos de esquemas, no formato de pirâmides, são muito pertinentes, pois demonstram que 0 lugar de privilégio, o topo, raramente representa a maioria e lembra também que o privilégio se constrói sobre uma base, como a base de uma pirâmide. Assim, todas as relações sexuais que não forem entre pessoas de sexo oposto, com papéis de gênero bem definidos, chanceladas por uma autoridade religiosa cristã, com finalidades reprodutivas, sem relação comercial e sem uso de acessórios que maximizem o prazer serão consideradas relações sexuais e de gênero inferiores, degradadas, praticadas pelas pessoas fora norma, pelos dissidentes sexuais e de gênero.

Nesse panorama, mesmo as relações heterossexuais permeadas pela prostituição e pelo fetiche são alvo de perseguições das forças e discursos conservadores. Portanto, os dissidentes são aqueles que desviam da norma, do ideal, do topo.

Exemplos dessas pessoas que desviam das normas são a travesti agressiva e a bicha afeminada, que constituem caricaturas icônicas nos programas e esquetes de humor da televisão brasileira desde os anos 1970 até os tempos atuais. Trevisan (2018) possui um capítulo em seu livro “Devassos no Paraíso" dedicado à questão da representação televisiva dos dissidentes sexuais e de gênero. 0 autor conclui que:

A verdade é que personagens homossexuais tendem a fazer tanto mais sucesso quanto maior for a curiosidade do público: a lógica perversa do mercado passa pela conveniente institucionalização do olhar voyer, amplamente explorada, em especial pela mídia eletrônica. Assim, reforçada por mais essa proibição, resguarda-se a necessidade de consumo mórbido da homossexualidade, com amplas conveniências comerciais. E dá-lhes gueis, lésbicas e travestis palatáveis na telinha. (TREVISAN, 2018, p. 292).

No caso da representação humorística das figuras dissidentes na TV, essa palatabilidade se operou por meio de estereótipos cômicos oriundos das expressões de gênero não lineares, muito especialmente, dos homens afeminados. Assim, as dissidências são eróticas e risíveis conforme horário e demanda do público. Um negócio versátil, lucrativo e desumanizante. Sobre os estereótipos, Miskolci (2015, p. 135) o define da seguinte maneira:

O estereótipo é a expressão cristalizada de desigualdades sociais herdadas por sociedades criadas em processos de subalternização de certos grupos sociais, os quais, especialmente no passado, tendiam a ser ignorados e, no presente, costumam ser hipervisibilizados como inferiores, anormais ou desviantes. 
A ridicularização midiática das pessoas sexo-gênero-dissidentes é também uma forma de hipervisibilidade, contudo, perniciosa. Por vezes, a forma com a qual a mídia televisiva tem tratado essas pessoas, reforça a desigualdade nas relações de poder entre os indivíduos, reproduzindo o binarismo de sujeitos 'normais' e 'anormais'.

Para além do humor, quando as personagens em dissidência surgiam na TV em um contexto mais 'sério', como nos dramas novelescos, suas imagens eram cuidadosamente descoladas de atuações eróticas. Sobre a relação da representação dos dissidentes nas novelas globais, Trevisan (2018) recorda que a TV Globo sempre tratou dos casais homossexuais com muita assepsia, sendo a primeira cena de sexo gay indo ao ar apenas em 2016 em uma novela das 23 horas (TREVISAN, 2018, p. 18).

Contudo, quando o objetivo era fazer graça para aqueles que possuem os privilégios da condição de normalidade sexual e de gênero, as portas do armário3 eram escancaradas e se arrancavam os sujeitos risíveis para o decadente espetáculo. Sedgwick (2007) lembra que o armário não é uma questão só dos dissidentes, mas também das pessoas normativas. 0 armário é uma relação de poder entre as pessoas (SEDGWICK, 2007, p. 38).

Em muitas relações, senão na maioria delas, assumir-se é uma questão de intuições ou convicções que se cristalizam, que já estavam no ar por algum tempo e que já tinham estabelecido seus circuitos de força de silencioso desprezo, de silenciosa chantagem, de silencioso deslumbramento, de silenciosa cumplicidade. Afinal, a posição daqueles que pensam que sabem algo sobre alguém que pode não sabê-lo é uma posição excitada e de poder - seja que o que pensem que esse alguém não saiba que é homossexual, ou meramente que conheçam o suposto segredo desse alguém. (SEDGWICK, 2007, p. 38).

Quer seja nas entrevistas, programas de humor, nos shows de calouros, ou nas novelas, sempre havia um espaço para arrancar do armário alguém que 'parecesse' não corresponder às expectativas da heteronormatividade4 e tornar essa pessoa (ou personagem) uma piada pronta em decorrência de seus modos de ser e se fazer gente. Contudo, quando a capacidade de produção midiática é democratizada, outras formas de humor são possíveis, abrindo espaço para novas possibilidades de representação.

\section{MÉTODO}

Utilizei como metodologia a análise do discurso em Foucault apoiada nos conceitos de enunciado, verdade, saber, poder e subjetividade. 0 enunciado é compreendido como o que atribui a uma proposição seu

3 Refiro-me ao armário como expressão popularmente conhecida para 'assumir-se' publicamente fora das normas sexuais e de gênero, mas também, baseado no texto de Sedgwick (2007), como uma relação de poder entre as pessoas que negocia os silêncios e revelações dessa condição.

$4 \mathrm{~A}$ heteronormatividade pode ser definida como a norma que regula, justifica e legitima a heterossexualidade como uma forma de sexualidade mais natural, mais válida e mais normal em detrimento das outras, vistas como negativas e inferiores (OLIVEIRA, 2017, p. 27). 
valor de verdade e o que delimita o sentido a uma frase (FOUCAULT, 2007). Saber e poder se implicam mutuamente e ambos contribuem na produção de subjetividade. Nas palavras do próprio Foucault (1987, p. 31):

\begin{abstract}
Temos antes que admitir que o poder produz saber (e não simplesmente favorecendo-o porque o serve ou aplicando-o porque é útil); que poder e saber estão diretamente implicados; que não há relação de poder sem constituição correlata de um campo de saber, nem saber que não suponha e não constitua ao mesmo tempo relações de poder. [] Resumindo, não é a atividade do sujeito de conhecimento que produziria um saber, útil ou arredio ao poder, mas o poder-saber, os processos e as lutas que o atravessam e que 0 constituem, que determinam as formas e os campos possíveis do conhecimento.
\end{abstract}

Acerca dos elementos discursivos, eles foram obtidos por meio das falas, imagens e comentários de dois vídeos do YouTube cujo tema gira em torno do humor de figuras dissidentes das normas sexuais e de gênero. Os autores dos comentários não são expostos, garantindo-se o anonimato. Contudo, seus comentários foram transcritos e são verificáveis por meio dos endereços virtuais disponibilizados como referências.

Os vídeos são esquetes de humor televisivo de diferentes décadas (1980 e 1990). Embora fosse possível acessar os vídeos pelo site de acervo virtual das próprias emissoras de televisão, escolhi o acesso pelo YouTube, pela razão de os vídeos terem sido lançados e discutidos pelos próprios internautas e não por uma demanda das emissoras.

\title{
4 RESULTADOS
}

No YouTube, é possível encontrar diversos vídeos com temáticas a respeito das dissidências sexuais e de gênero. Os formatos dos vídeos são os mais diversos, educativos, cômicos políticos etc. A sessão de comentários existe (dentre outras funções) para que os expectadores deixem suas impressões sobre o conteúdo assistido.

Nesse espaço virtual que anseia por curtidas, visualizações e comentários, há uma disputa pelas verdades, tornando mais oportuno o trabalho de separá-las em termos de enunciados. Assim, descrevo a seguir os dois vídeos selecionados, bem como os principais comentários que evidenciam os enunciados a serem trabalhados:

Vídeo 1 - Capitão Gay $^{5}$ (1982)

Descrição do vídeo:

Em um escritório (bancário?) um homem (cliente) reivindica seus rendimentos e é impedido pela burocracia de um comprovante chamado "receita líquida". Os atendentes (um homem e uma mulher) declaram que não há na Terra nenhum homem ou mulher capaz de resolver esse problema. 0 cliente

5 Disponível em: https://www.youtube.com/watch?v=zydfPLPqUcc\&t=2s. Acesso em: 29 ago. 2019. 
então diz que o Capitão Gay pode resolver seu problema e o invoca. O herói surge ao som de sua típica canção acompanhado de seu assistente Carlos Suely. Segue a canção: "É o defensor das minorias (gay!) / E é sempre contra as tiranias (gay!) / É avião, passarinho sem rabicho? / Ou se parece mais com outro bicho? / É o Capitão Gay, gay, gay! / Capitão Gay / Capitão Gay!”

Após o cliente relatar o problema aos super-heróis eles preparam um drink e o jogam no rosto dos atendentes dizendo que essa é a receita líquida. Então o cliente agradece aos heróis e a esquete termina com a trilha sonora do Capitão Gay.

Acerca dos comentários, até a data do meu último acesso, o vídeo contava com 65 comentários, muitos dos quais eram reações de risos e lembranças de nostalgia. Os comentários destacados abaixo foram escolhidos pelos enunciados que se articulam com a discussão deste artigo.

“Legal essa época que não existia o politicamente correto".

"Hoje seria preconceito. O Brasil já foi legal, até a globo já foi legal”.

"Hoje em dia da cadeia... Isto é do tempo que o Jô Soares, não era vendido e podia fazer piadas".

"Se isso passasse na tv hoje em dia daria uma treta... Já to ate vendo um monte de pseudo-conservador e defensores da moral dizendo ESSES GAY NA TELEVISÃO INFLUENCIANDO AS CRIANÇA A DAR O CU, É UMA POUCA VERGONHA".

"Que saudade! Todas as segundas-feiras eram sagradas".

\section{Enunciados}

1 - 0 politicamente correto impede a liberdade do humor.

2 - Nostalgia de um tempo em que se podia usar as figuras da dissidência sexual e de gênero para produzir humor para o grande público.

3 - Exibir os gays na TV influenciam a homossexualidade infantil.

Vídeo 2 - Vera Verão ${ }^{6}(1998)$

Descrição do vídeo:

Um diretor de cinema pede a Carlos Alberto um espaço emprestado da Praça para ensaiar uma cena de seu filme, acompanhado de seus atores que interpretam as personagens Jane e Tarzan, mas o ensaio é interrompido com a chegada de Vera Verão. A personagem de Jorge Lafond procura saber o que está havendo, e, ao descobrir, insulta e desqualifica a atriz.

0 diretor convencido dos argumentos (embora ofensivos) acaba por desistir da moça optando pela travesti. A travesti se recusa a fazer o papel da atriz e, ao avistar o ator que interpreta Tarzan, leva- o embora e diz que prefere ser sua macaca Chita pois está interessada no tamanho de sua banana. Sobre os comentários, ressalto que até o momento da pesquisa de campo o vídeo possuía 15 comentários. A maioria dos comentários era de reações de riso e nostalgia por conta da morte prematura do intérprete de Vera Verão.

6 Disponível em: https://www.youtube.com/watch?v=ET2l/4Fpolc. Acesso em: 29 ago. 2020. 
O HUMOR DE ANTIGAMENTE ERA POLITICAMENTE INCORRETO HOJE AS COISAS MUDARAM O HUMOR DE HOJE É COM A Internet

Saudades da época em que os humoristas eram tão naturais. Verão verão será eterna. Hahaha por isso era o melhor quadro da Praça é nossa! Sds Laffond!

Enunciados:

1 - O humor na TV permitia a liberdade do politicamente incorreto que hoje a Internet limita;

2 - Saudades da produção humorística de uma época.

Embora a amostra de campo seja reduzida a dois vídeos e oito comentários, são os enunciados, em sua intrínseca raridade (FOUCAULT, 2007) que nos interessam. Esses enunciados, embora raros, repetem-se em milhares de outros vídeos e comentários no YouTube.

\section{DISCUSSÃO}

A escolha dos vídeos acontece por se tratar de duas personagens consagradas no cenário nacional da comédia televisiva. Personagens que marcaram época e se encontram até hoje nas lembranças e no imaginário das gerações que acompanharam seus trabalhos. Além disso, a grande visibilidade que esses vídeos alcançaram, permitem uma análise de seus comentários no YouTube.

Por sua vez, ao se constituir não apenas como uma plataforma de lançamento de vídeos, mas também uma rede social, o YouTube coloca os internautas em relações discursivas muito próprias, relações sociais intermediadas por um meio virtual, produtoras de fenômenos que não seriam possíveis na TV, como as produções/edições de conteúdo audiovisual, curtidas, denúncias, compartilhamentos e comentários. Então é nessa trama discursiva produzida com outras tecnologias, em outros tempos que buscamos as reverberações discursivas dos enunciados nessa interface da TV com a Internet.

Sobre o primeiro vídeo, a construção dos heróis gays satirizam os modelos de heróis viris da cultura de massas (TREVISAN, 2018), ao mesmo tempo em que recorrem à estereótipos de comportamento gay, além de uma estética drag queen. Trevisan (2018, p. 293) diz que "o Capitão Gay ironizava tanto à direita quanto à esquerda", visto que esse personagem era acusado de, por um lado, ser uma influência homossexualizadora e de outro, ser um desserviço à militância por tornar o gay "objeto de riso nacional".

A negra de quase dois metros de altura, Vera Verão, era a encarnação do estereótipo da travesti encrenqueira; brigava com as mulheres e disputava com elas o homem da vez em cada episódio. Geralmente, a travesti desbancava as moças e fisgava para si o homem disputado.

Embora haja críticas quanto às representações estereotipadas dos personagens e suas estreias na TV fossem o motivo do riso, uma coisa é certa, elas já não eram invisíveis. Além disso, conforme já dissera Trevisan (2018), mesmo em um contexto humorístico, essas figuras assombravam muita gente com o fantasma da "influência homossexual". 
Todavia, uma aceitação (ou tolerância) de um grupo minoritário que se sustenta por meio de sua condição risível, erótica e sub-humana não condiz com a dignidade que norteia o ideal de humanidade para todos os seres humanos. Junqueira (2013, p. 493) aprofunda essa discussão ao lembrar que:

é recorrente o entendimento de que respeitar o 'outro' seria um gesto humanitário, expressão de gentileza, delicadeza ou magnanimidade. Uma espécie de benevolente tolerância que deixa ilesas hierarquias, relações de poder e técnicas de gestão das fronteiras da normalidade. Informadas por uma matriz de conformação, pessoas com distintos graus de preconceitos costumam se perceber dotadas de atributos positivos por crerem-se portadoras de certa sensibilidade em relação às vítimas - uma dose de compaixão, em função da qual o 'outro' recebe uma aquiescente autorização para existir, em geral, à margem e silenciado.

A partir da leitura de Junqueira, entendo que, uma visibilidade sustentada pela ridicularização das dissidências é uma existência marginal que reforça relações de poder que sustentam a heterossexualidade e cisgeneridade como norma.

Ao analisar as imagens e discursos dos vídeos, deparo-me com comentários emblemáticos da percepção humorística. Em geral, os comentários carregam o enunciado de que o politicamente correto de hoje é o responsável pelo declínio do "humor de qualidade" e que a Internet fiscaliza o humor, além disso, há uma noção bem difundida nos comentários de que naquelas épocas, do humor televisivo, era possível "rir livremente" das dissidências sem sofrer consequências ou censuras.

Nas palavras dos próprios internautas - insatisfeitos com o rumo que tomou o humor no Brasil hoje -, algumas dessas consequências na produção desse formato de humor seriam: "crime", "preconceito" e "politicamente incorreto". Assim, quando as pessoas subalternizadas reivindicam respeito na rede, elas são acusadas de exigir privilégios justamente daqueles que detém de fato os privilégios da 'normalidade' sexual e de gênero.

Ocorre que na Internet, por meio das redes sociais, pessoas e grupos se manifestam para questionar, debater e enfrentar as produções da grande mídia. A transmissão de conteúdo verticalizada da televisão agora tem sua hegemonia abalada pela ampliação da Internet no Brasil e, graças a isso, tem surgido um debate que tem feito a própria televisão questionar sua produção humorística conforme mostrado na série documental "Viver do Riso7" da atriz Ingrid Guimarães.

Em um dos episódios a atriz entrevista colegas para conversar sobre como a mudança na sociedade tem feito o humor se repensar e produzir coisas novas. Existe um grande público que não aceita mais as antigas formas de humor produzidas tradicionalmente pela TV.

A mídia televisiva, percebendo esse nicho, promove algum grau de abertura para a promoção de um humor 'inclusivo' em alguns programas, por exemplo, “Amor e sexo" que satiriza os padrões da masculinidade tóxica em prol da liberdade sexual e do programa "220 volts" de Paulo Gustavo ator assumidamente gay que debocha dos preconceituosos.

Entretanto, o primeiro programa mencionado fica na faixa de horário após 23:00 horas e o segundo é disponível apenas para canal pago. O horário nobre da TV Globo e das demais emissoras continuam a reproduzir caricaturas, polêmicas e excentricidade das dissidências sexuais e de gênero.

7 Disponível em: https://globoplay.globo.com/v/7505028/. Acesso em: 29 ago. 2019. 
Entretanto, o espaço da rede virtual não se limita a criticar o humor duvidoso que perpetua condições de estigma para populações que não se encaixam nas expectativas hegemônicas de sexo/gênero. Segundo o humorista Gregório Duvivier, em entrevista8 ao Dr. Drauzio Varela, o espaço virtual tem produzido conteúdo viral de humor como forma de resistência aos formatos estereotipados do humor televisivo.

Duvivier entende que no território virtual, já não são aceitas, tão facilmente, as antigas fórmulas de humor tão caras à televisão. Existe espaço para uma produção humorística alternativa; pelo menos para uma parte dos internautas, a noção do respeito às composições subjetivas e experiências de vida de determinadas populações frente às violências físicas e simbólicas sofridas, levam ao questionamento sobre o riso da dor do outro que é perpetrado historicamente.

Por outro lado, o panorama exposto está longe de ser um refúgio inatingível. Há uma parcela de internautas que não apenas se comprazem nas velhas formas de humor que procuram tripudiar das subjetividades desviantes como reforçam mensagens de extermínio e preconceito na rede, são os chamados haters 9 .

Não há de um lado, uma mídia televisiva maligna que fabrica escárnio dos dissidentes e de outro uma Internet redentora que resgatará os aflitos. Há estigma e resistência de ambos os lados. 0 que se passa na televisão, é que suas produções divididas em nichos perpetuam em larga escala o preconceito e a zombaria dos modos de vida dissidentes, enquanto as formas de resistência de humor ficam relegadas aos horários de menor audiência e aos canais pagos.

Por outro lado, a Internet, ainda que seja uma zona cercada de discursos de ódio, ainda guarda uma relativa autonomia de produção e circulação de conteúdos humorísticos de viés político com comprometimento ético. Como bem lembra Foucault (1984, p. 349-350), mais importante que verificar se as representações correspondem à realidade, é perceber as condições que possibilitam que essas representações surjam como são e, as possibilidades de reação nesse jogo de poder. 0 que na rede, significa os usos possíveis das ferramentas virtuais para ressignificar o humor enquanto relação de poder e não a construção de uma imagem ideal e definitiva das dissidências.

Existem hoje, na rede, vários influenciadores10 digitais dissidentes das normas sexuais e de gênero, produzindo diversos conteúdos de humor com temática de diversidade sexual e de gênero. Citamos como exemplo dois influenciadores digitais de grande alcance na rede: Pedro HMC (canal Põe na roda que já conta com um milhão de inscritos) e Lorelay Fox (canal Para Tudo com quase setecentos mil inscritos). Eles usam os espaços do YouTube, Facebook, Instagram e Twitter para produzir humor, informação, entretenimento e militância na rede.

Esses influenciadores levantam temas tanto atuais quanto tradicionais do universo LGBT e fazem o enfrentamento da opinião pública conservadora em suas respectivas páginas. Eles operam o

8 Disponivel em: https://www.youtube.com/watch?v=MNOWeBfhTtE\&list=PLLcA2I5B3SEOmKJn208Lh0Gkj2B-Hhg3W\&index=2 Acesso em: 17 set. 2019.

9 Segundo o site 'Significados' haters é uma palavra de origem inglesa e que significa "os que odeiam" ou "odiadores" na tradução literal para a língua portuguesa. 0 termo hater é bastante utilizado na Internet para classificar algumas pessoas que praticam "bullying virtual" ou "cyber bullying" (HATERS, 2018)

10 Segundo Verissimo (2019), influenciador digital é toda pessoa que possui a capacidade de influenciar pessoas, lançar tendências e formar opiniões sobre determinado assunto por meio de plataformas digitais. 
humor LGBT num sentido reverso. A figura do homofóbico (por exemplo) é ridicularizada e tornada motivo de riso na rede.

As expressões sexuais e de gênero dissidentes são celebradas e empoderadas nesses canais. Além disso, esses espaços midiáticos alternativos convidam várias pessoas da comunidade para contar suas histórias e experiências num formato educativo, engajado e bem-humorado. Alguns quadros do canal Põe na Roda contam também com participação de profissionais para conversar sobre questões pessoais, familiares e de trabalho.

Na sessão de comentários, os internautas interagem diretamente com os influenciadores com dicas, sugestões, críticas, conselhos, opiniões e desabafos, formando uma verdadeira rede de solidariedade virtual. Muitos internautas manifestam sua gratidão aos influenciadores pelo conteúdo dos vídeos que servem de inspiração para superação de problemas pessoais e disparadores de diálogos delicados com a família sobre as questões da sexualidade e gênero.

Quanto à televisão, esta tem dado sinais de mudança nos seus formatos humorísticos, buscando diálogos, inspirações e importações de modelos que já fazem sucesso na Internet a fim de cativar um outro perfil de público. Independente do formato da mídia, nota-se que no atual momento histórico, as pessoas que desviam das normas sexuais e de gênero não são apenas as criaturas risíveis e exóticas de outrora, são também um significativo nicho de mercado, mas principalmente, são pessoas capazes de se organizar e lutar por uma estética de vida mais autônoma, construindo ativamente outros espaços de (re)existência na sociedade.

\section{CONCLUSÃO}

A Internet transformou a forma como as pessoas interagem com a mídia, não apenas na esfera do consumo, mas também de produção de conteúdo midiáticos. Na rede, as reações para as velhas formas de humor estereotipadas sobre as dissidências chegam instantaneamente, seja na forma de comentários ou na criação de novos conteúdos. Toda essa trama discursiva audiovisual que se multiplica na rede carrega verdades, não necessariamente novas, mas capazes de mobilizar multidões na disputa por sentidos, os mais diversos.

Nessas disputas, importa destacar que as verdades suscitadas não guardam compromisso com objetividade científica ou neutralidade, mas antes, produzem efeitos subjetivadores, por vezes estigmatizantes, mas sempre passíveis de resistência. Produzir na rede é transformar a realidade, é construir um mundo sustentado por um compromisso ético na relação com os outros.

\section{REFERÊNCIAS}

ALONSO, Nilton Tadeu de Queiroz. Entre segredos e risos: gírias da diversidade sexual paulistana. 233f. 2010. Tese (Doutorado em Língua Portuguesa) - Pontifícia Universidade Católica de São Paulo, São Paulo, 2010. 
CARNIEL, Fagner; RUGGI, Lennita; RUGGI, Júlia de Oliveira. Gênero e humor nas redes sociais: a campanha contra Dilma Rousseff no Brasil. Opinião Pública, Campinas, v. 24, n. 3, p. 523-546, set.-dez. 2018.

FOUCALT, Michel. A arqueologia do saber. Tradução de Luiz Felipe Baeta Neves. 7 ed. Rio de Janeiro: Forense Universitária, 2007.

FOUCAULT, Michel. Vigiar e punir: nascimento da prisão; tradução de Raquel Ramalhete. Petrópolis, Vozes, 1987. 288 p.

FOUCAULT, Michel. “What is Enllgthenment?” (“O que são as Luzes?”). In. Rabinow (P), ed. The Foucault reader. Nova Iorque, Pantheon Books. 1984. p. 32-50. Disponível em: http://www. eduardoguerreirolosso.com/FOUCAULT-o-que-s\%C3\%A3o-as-luzes.pdf. Acesso em: 4 nov. 2019.

GONZATTI, Christian. Bicha, a senhora é performática mesmo: sentidos queer nas redes digitais do jornalismo pop. 2017. Dissertação (Mestrado) - Universidade do Vale do Rio dos Sinos, Programa de Pós-graduação em Ciências da Comujnicação, São Leopoldo, RS, 236 f. 2017. Disponível em: http:// www.repositorio.jesuita.org.br/handle/UNISINOS/6902. Acesso em 09 dez. 2019.

HATERS. Dicionário on-line Significados, 17 de set. 2019. Disponível em: https://www. significados.com.br/haters/. Acesso em: 17 set. 2019.

JUNQUEIRA, Rogério Diniz. Pedagogia do armário A normatividade em ação. Revista Retratos da Escola, Brasília, v. 7, n. 13, p. 481-498, jul.-dez. 2013. Disponível em: retratosdaescola.emnuvens. com.br/rde/article/download/320/490. Acesso em: 29 ago. 2019.

MAZOTI, Patrícia Aurora Corrêa. Põe na roda: entre conexões e conectividades nas mídias digitais. 2018, 146f. Dissertação (Mestrado em Ciências Sociais) - Universidade Estadual Paulista (Unesp), Faculdade de Filosofia e Ciências, Disponível em: https://repositorio.unesp.br/ handle/11449/155861. Acesso em: 9 dez. 2019.

MISKOLCI, Richard. Do armário à discrição? Regimes de visibilidade sexual das mídias de massa às digitais. In.: PELÚCIO, Larissa. No emaranhado da rede: gênero, sexualidade e mídia, desafios teóricos e metodológicos do presente. São Paulo: Annablume, 2015. 272p.

OLIVA, Thiago Dias. Memes de natureza cômica como estratégia de resistência a discursos hegemônicos: análise das reações à campanha \#gaysnomerecenmedallas no twitter. Linguagem em (Dis)curso - LemD, Tubarão, SC, v. 18, n. 3, p. 583-601, set./dez. 2018. Disponível em: http://www. scielo.br/scielo.php?script=sci_abstract\&pid=S1518-76322018000300583\&lng=en\&nrm=iso\&tlng= pt. Acesso em: 9 dez. 2019. 
OLIVEIRA, João Manuel de. Desobediências de gênero. Salvador, BA: Editora Devires, 2017.

RUBIN, Gayle. Políticas do sexo. Tradução: Jamille Pinheiro Dias. São Paulo: Ubu editora, 2017.

SEDGWICK, Eve Kosofsky. A epistemologia do armário. Cad. Pagu, Campinas, n. Jundiaí 28, p. 19-54, June 2007. Disponível em: http://www.scielo.br/scielo.php?script=sci_ arttext\&pid=S0104-83332007000100003\&lng=en \&nrm=iso. Acesso em: 22 out. 2019.

TREVISAN, João Silverio. Devassos no Paraíso: a homossexualidade no Brasil, da colônia à atualidade. 4. ed, rev., atual. e amp. Rio de Janeiro: Objetiva, 2018.

VERISSIMO, Pedro. Influenciador digital, definição, conceitos básicos e tipos de influência. Influnews. com.br. 12 nov. 2019. Disponível em: https:// influnews.com.br/influenciador-digital-definicaoconceitos-basicos-e-tipos-de-influencia/. Acesso em: 9 dez. 2019.
Recebido em: 30 de Março de 2018

Avaliado em: 5 de Maio de 2018

Aceito em: 10 de Agosto de 2018

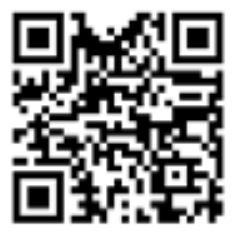

A autenticidade desse artigo pode ser conferida no site https://periodicos. set.edu.br
Como citar este artigo:

ROMEO, Andrea. Lo special account del fenomeno religioso nel dibattito nordamericano. Argumenta Journal Law, Jacarezinho - PR, Brasil, n. 29., 2018, p. 15-48. DOI: 10.17564/2316-3828.2018v7n1p13-24

\section{(2) (1) (2)}

Este artigo é licenciado na modalidade acesso abertosob a Atribuição-Compartilhalgual CC BY-SA
1 Mestrando em Psicologia, Institucional Universidade Federal do Espírito Santo; Assistente Social.

E-mail: socialrafael89@gmail.com 
